\title{
Nursing Students Perceptions on the Use of Preceptors to Improve Clinical Competence at the University of Namibia
}

\author{
Simon Paulus ${ }^{1}$, Daniel Opotamutale Ashipala ${ }^{1}$, Kristofina Amakali ${ }^{2} \&$ Aron Kamenye Aron ${ }^{3}$ \\ ${ }^{1}$ Department of General Nursing Science, School of Nursing, Faculty of Health Sciences, University of Namibia \\ (UNAM), Rundu, Namibia \\ ${ }^{2}$ Department of General Nursing Science, School of Nursing, Faculty of Health Sciences, University of Namibia \\ (UNAM), Main Campus, Namibia \\ ${ }^{3}$ Namibia Institute of Pathology (NIP), Ministry of Health and Social Services, Namibia \\ Correspondence: Daniel Opotamutale Ashipala, MNSC, Department of General Nursing Science, School of \\ Nursing, Faculty of Health Sciences, University of Namibia (UNAM), P. O. Box 88 Kaisosi Road, Rundu, \\ Namibia. E-mail: dashipala@unam.na
}

Received: January 9, 2019 Accepted: September 4, 2019 Online Published: September 16, 2019

doi:10.5539/gjhs.v11n11p92 URL: https://doi.org/10.5539/gjhs.v11n11p92

\begin{abstract}
The purpose of this study was to investigate the perceptions of nursing students in relation to the use of preceptors to improve their clinical competence at the School of Nursing at the University of Namibia. Thus, the objectives of the study were to assess and describe the perceptions of nursing students regarding the use of preceptors to improve their clinical competence with a view to make recommendations based on the findings of the study. A quantitative, descriptive, cross-sectional design was used with a total of 100 nursing students from all four cohorts for the Bachelor of Nursing (Honours) (Clinical) at one of the university campuses being conveniently to participate in the study. Self-administered questionnaire were used to collect the data from the participants. The data derived from the questionnaire was analysed using SPSS version 24. The findings from the study revealed, inter alia, that $70 \%$ of the participants indicated that the use of preceptors has a positive effect on the students' clinical competence. The study therefore recommended sustainment and strengthening of preceptorship strategies for clinical accompaniment of students. Notwithstanding positive findings, the study also recommends improvement of skills for teaching and time management skill, punctual report on duty and efficient utilization of clinical time for preceptors for more efficient implementation of student teaching during clinical accompaniment.
\end{abstract}

Keywords: clinical competence, nursing students, preceptors

\section{Introduction}

There is evidence that globally, the majority of health programmes depend on preceptors to facilitate the transformation of student nurses into professional nurses. While clinical practice provides the opportunity for enhancing and complementing the students' learning, preceptors facilitate transformation of student nurses into professional nurses (Tangwa \& Shehnaaz, 2018). During practice, both nursing staff and nursing lecturers are expected to team up to cooperate to help the students both to develop clinical skills and professional confidence. Thus, the preceptor role involves creating a positive learning atmosphere in which theory and practice complement each other (Mashaba \& Brink, 2016), in collaboration with registered nurses in clinical setting in respect of the intended learning outcomes of the students' clinical learning time.

If the students are to acquire sufficient knowledge and skills during their clinical practice, it is essential that someone is assigned to accompany and mentor them and also to show them how theoretical knowledge may be combined with practice (Bruce, Klopper, \& Mellish, 2015). The students must be assisted to meet the clinical learning requirements in order to ensure the adequate preparation of nursing students and their attainment of the clinical competence they need to enable them to practise nursing effectively (Burns \& Grove, 2014). Holloway and Wheeler (2010) describes a preceptor as a skilled registered nurse who is able to provide students with the assistance and experience they require to facilitate their clinical learning. Thus, students work under the supervision of registered nurses and clinical preceptors who provide ongoing support to assist them with their clinical learning. 
In Namibia, the clinical teaching of nursing students involves the "one teacher" model in terms of which the nursing lecturers have dual responsibility for both lecturing and clinical teaching. There has been an increase in student enrolment at the University of Namibia, thus leading to an increased workload for the nursing lecturers as they struggle to perform the increased teaching, administration work and research activities. It would appear that, as a result, lecturers have insufficient time to provide adequate clinical support to student nurses due to the fact that they have to teach theory and, at the same time, incorporate it into practice (Mellish, Brink, \& Paton, 2016).

Consequently, in 2017 the School of Nursing at the University of Namibia has introduced preceptorship to assist nursing students in acquiring the required clinical competence. These preceptors provide their services to the university for five (5) days per week, for a minimum of twenty (20) or a maximum of twenty-five (25) hours per week. For the first time all the university campuses which offer the Bachelor of Nursing Science are using this system. At the time of the study three (3) preceptors had been appointed at the specific campus to carry out the clinical accompaniment to the first, second, third and fourth year cohort of students.

However, it would seem that little is known whether this preceptorship system is fulfilling its intended purpose since the strategy was introduced for the first time from the academic year 2017 on the specific campus. In addition, since the Nursing School is new on the campus, both the lecturers and preceptors are also relatively new. Therefore, little is known about how the student nurses perceive the use of preceptors in relation to improvement of their clinical competence. Thus, the study sought to answer the following research question: What are the perceptions of nursing students regarding the use of preceptors to improve their clinical competence?

\section{Goals and Objectives}

The goal of the study was to investigate the perceptions of nursing students regarding the use of preceptors to improve the clinical competence of nursing students at one of the campus of the University of Namibia. The research objectives were to assess and describe the perceptions of nursing students regarding the use of preceptors to improve their clinical competence at the School of Nursing.

\section{Methods}

\subsection{Design}

The study used a cross-sectional, quantitative, descriptive research design. Quantitative approach is deemed to be an efficient and inexpensive method to collect data from a large number of respondents in a survey (Brink, van Rensburg, \& van der Walt, 2018)

\subsection{Setting}

This study was conducted at the School of Nursing, Rundu Campus - One of the satellite campuses of the University of Namibia. There were 234 registered nursing students at the university in 2018.

\subsection{Study Population}

The study population for the study comprised all 234 registered students enrolled for the Bachelor of Nursing Science (Clinical) (Honours) at the School of Nursing at the Rundu Campus.

\subsection{Inclusion and Exclusion Criteria}

All the nursing students enroled for the Bachelor of Nursing Science (Honours) (Clinical) for the 2018 academic year at the specific campus and who were not willing to participate in the study were included in the study Students not enrolled for the Bachelor of Nursing Science (Honours) (Clinical) for the 2018 academic year and who were not willing to participate in the study were excluded from the study.

\subsection{Sampling and Sample Size}

The study sample of 122 was calculated from the study population of 234 , based on $95 \%$ confidence interval (CI) and 5\% confidence error. Particpants were randomly selected from the list of 234 nursing students to ensure an equal chance for participation (Brink et al., 2018). A total number of 122 nursing students were selected.

\subsection{Data Collection Tool}

The requisite data was collected using questionnaires as the data collection tool as the questionnaire was considered to be a relevant tool to collect data from a larger sample (Polit \& Beck, 2016). A total number of 122 data collection instruments were prepared.

\subsection{Data Collection Methods}

A total of 122 questionnaires were distributed to the participants. Of this total, 100 questionnaires were completed and returned. Thus completed questionnaire yielded $82 \%$ sample achievement. 


\subsection{Data Analysis}

The data which had been collected was analysed using computerised statistical techniques as contained in SPSS version 24. The findings were then presented as descriptive statistics.

\section{Ethical Considerations}

This study was approved by the School of Nursing Research Ethics Committee of the Faculty of Health Sciences at the University of Namibia (SoNREC 01/2018). All the participants were assured of both confidentiality and anonymity with anonymity being maintained except with regard to gender, age and educational background. Participation in the study was voluntary and the participants were required to sign informed consent forms prior to participation. In addition, they were also informed that they were free to withdraw from the study at any stage. All the research material and relevant documents with responses were stored safely in an area accessible only to the researcher.

\section{Results}

\subsection{Socio-Demographic Description of Study Participants}

\subsubsection{Age of Participants $(\mathrm{n}=100)$}

Table 1. Distribution of respondents according to age

\begin{tabular}{lll}
\hline Age of participants & & \\
\hline & Responses (n) & Frequency \% \\
\hline 18 to 20 years & 22 & 22 \\
21 to 24 years & 55 & 55 \\
25 to 29 years & 8 & 8 \\
30 to 34 years & 13 & 13 \\
35 and above & 2 & 2 \\
Total (n) & 100 & 100.0 \\
\hline
\end{tabular}

Table 1 above depicts the age ranges of the nursing students who participated in the study. It indicates that the majority of the respondents were 55, namely, (55\%) were between the ages of 21 and 24 years. There were very few respondents between the ages of 18 and 20 years, because majority of particpants were in their second to fourth year of studies.

\subsubsection{Gender Distribution of Respondents}

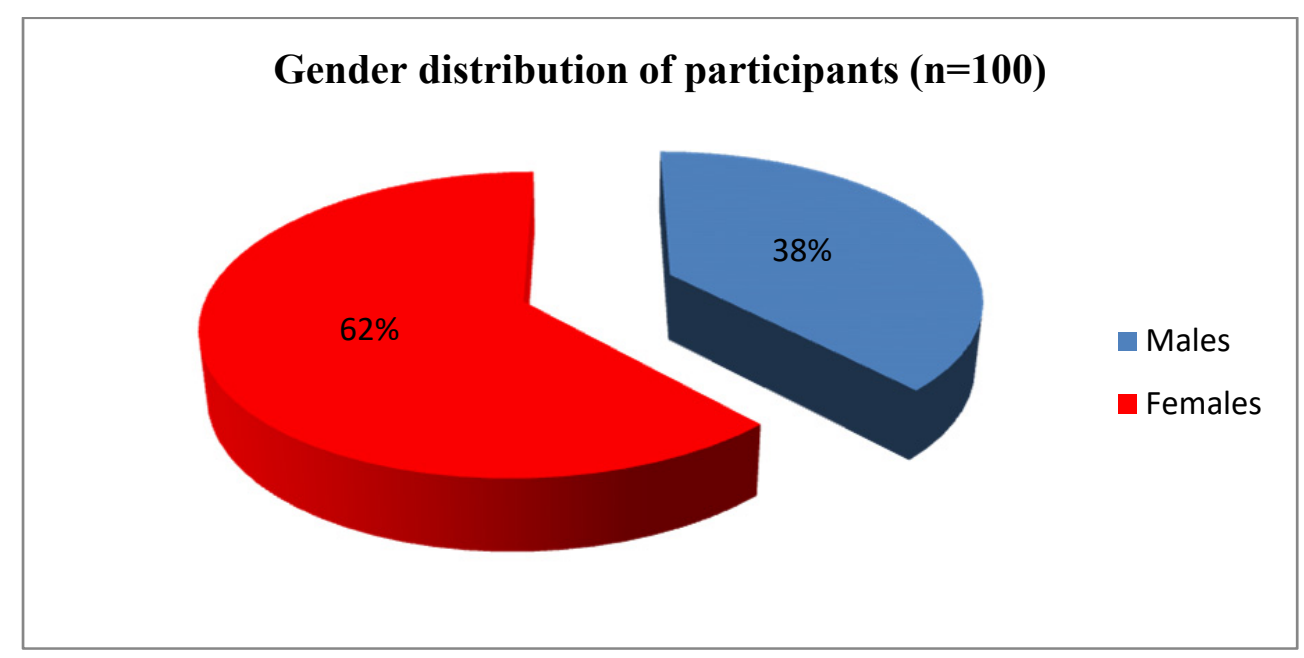

Figure 1. Distributions of respondents according to gender 
Figure 1 illustrates the distribution of the respondents by gender. Of the total of 100 respondents who participated in the study, $62(62 \%)$ were female while only $38(38 \%)$ were male.

\subsubsection{Level of Academic Year of Participants}

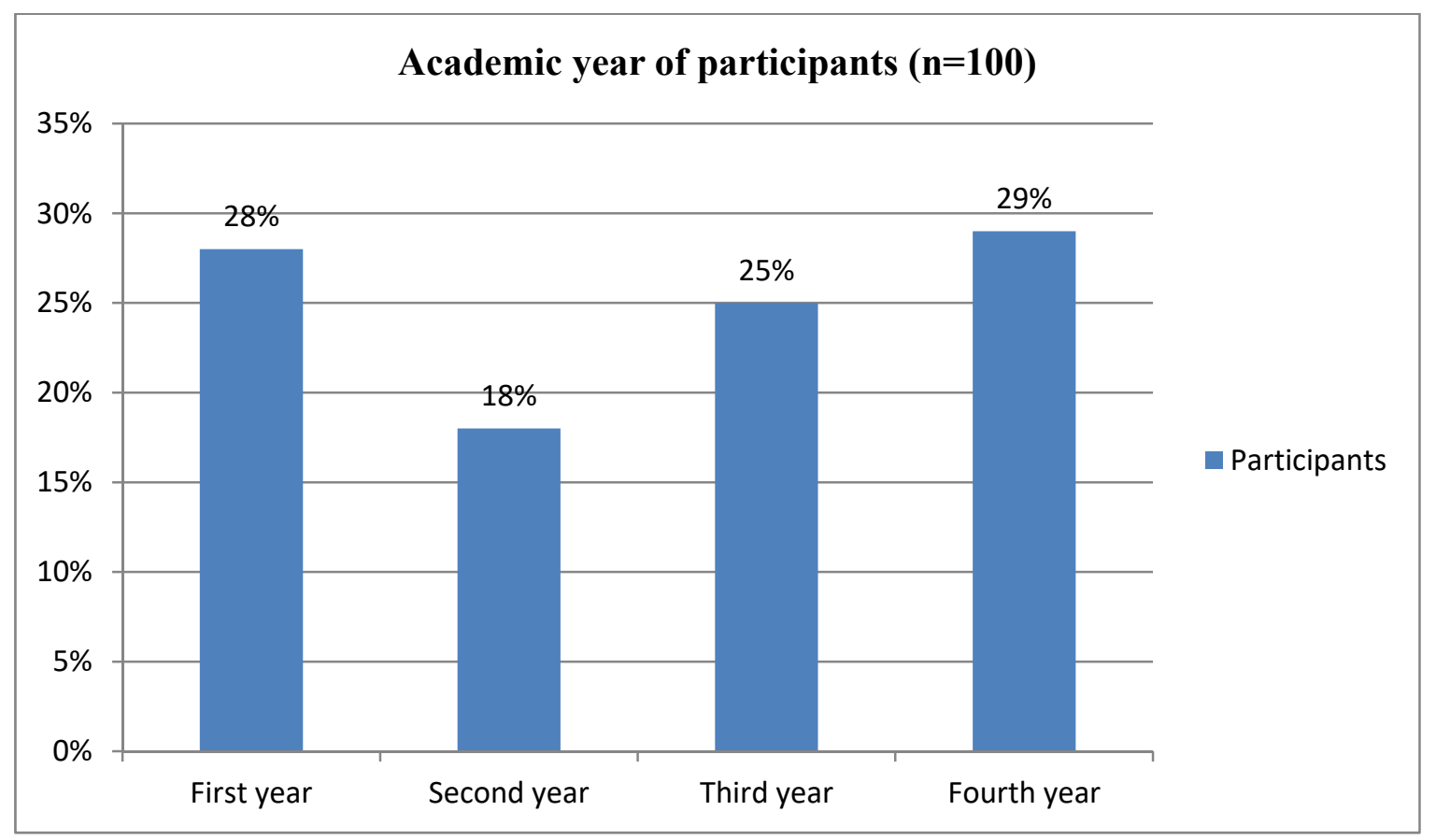

Figure 2. Participants' level of study

Figure 2 presents the representation of the participants at the School of Nursing at the campus of study (Rundu Campus). The majority of $29(29 \%)$ were in fourth year, 28 (28\%) were in first year, $25(25 \%)$ were in third year while $18(18 \%)$ were in the second year of their studies.

5.1.4 Clinical Teaching $(\mathrm{n}=100)$

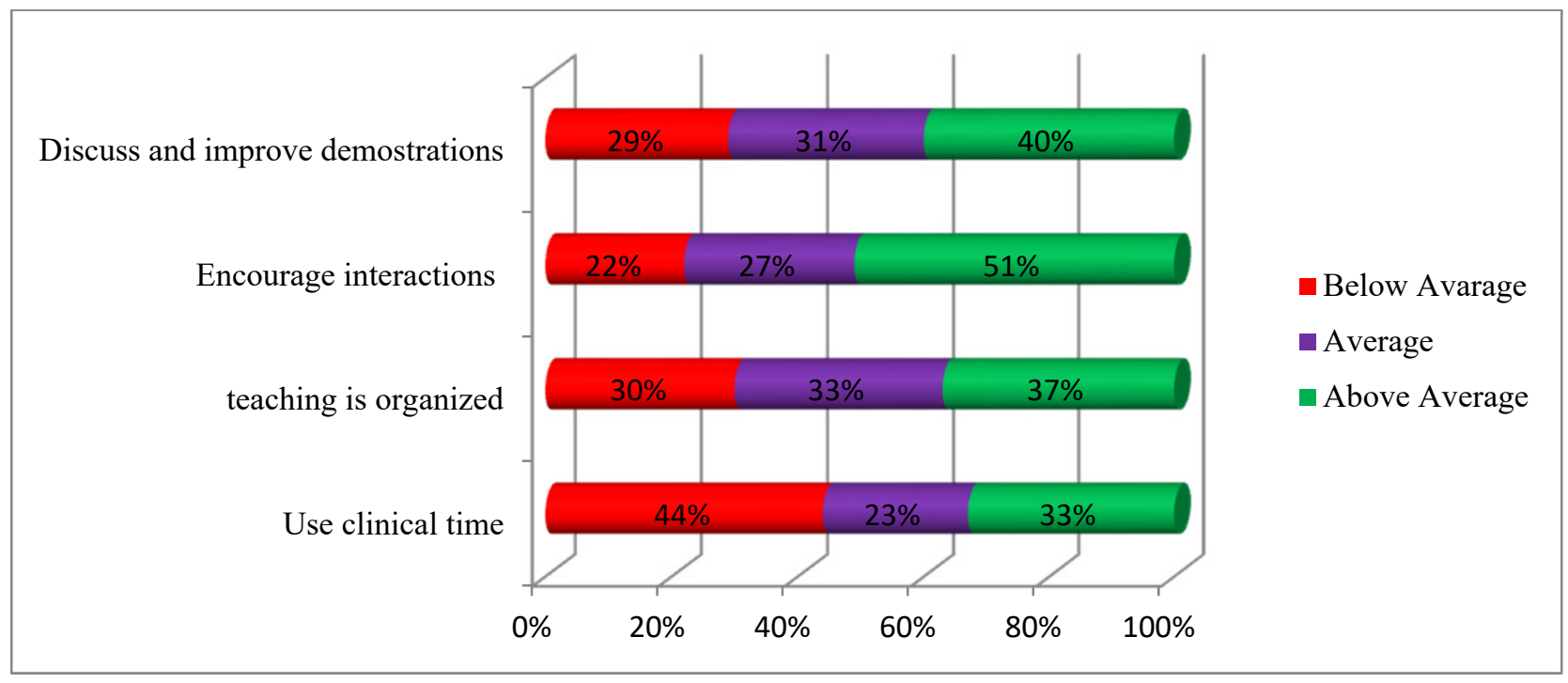

Figure 3. Students' perceptions of the overall clinical teaching by preceptors 
Figure 3 above indicates that the majority 44 (44\%), of the participants, rated the preceptors' use of clinical time as below average, while 37 (37\%) rated their perceptions of the organisation of the clinical teaching as above average, $51(51 \%)$ rated the preceptors' encouragement of interaction among students as above average while $40(40 \%)$ rated the preceptors' discussing and improving demonstrations as above average.

5.1.5 Student Support $(\mathrm{n}=100)$

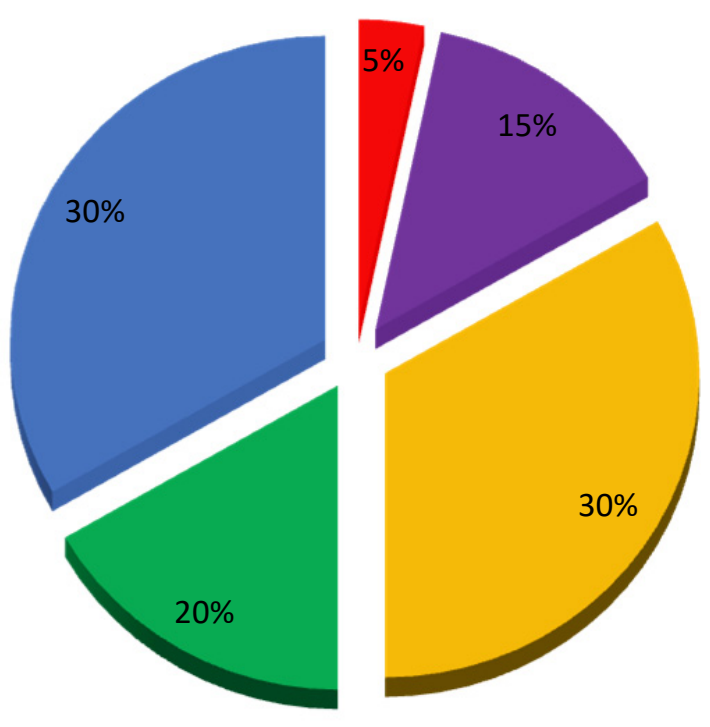

Availability of preceptors

Treatment of students by preceptors

Provision of feedback

Facilitation of cofident level

Facilitation of critical thinking

Figure 4. Students' perceptions regarding the overall student support provided by preceptors

The figure above revealed that $30 \%(n=30)$ of the respondents in the study were of the opinion that the preceptors provided helpful feedback on demonstrations, thus implying that the remaining $70 \%$ were not of this opinion. The figure also showed that $30 \%(n=30)$ of the respondents reported that the preceptors facilitated critical thinking on their behalf, leaving $70 \%$ of respondents as disagreeing that the preceptors did this while $20 \%(\mathrm{n}=20)$ were of the view that the preceptors surely boosted their confidence, thus indicating that $80 \%$ of the respondents did not feel this way. In addition, treatment of students with respect by preceptors with $15 \%(\mathrm{n}=15)$ of the respondents, the remaining $85 \%(n=85)$ expressing the opposite view. Finally, the availability of preceptors in the clinical setting was scored the lowest with $5 \%(n=5)$ only, while the remaining $95 \%(n=95)$ of the respondents disagreed that preceptors turn up regularly for clinical accompaniment.

5.1.6 Professional Conduct $(\mathrm{n}=100)$ 


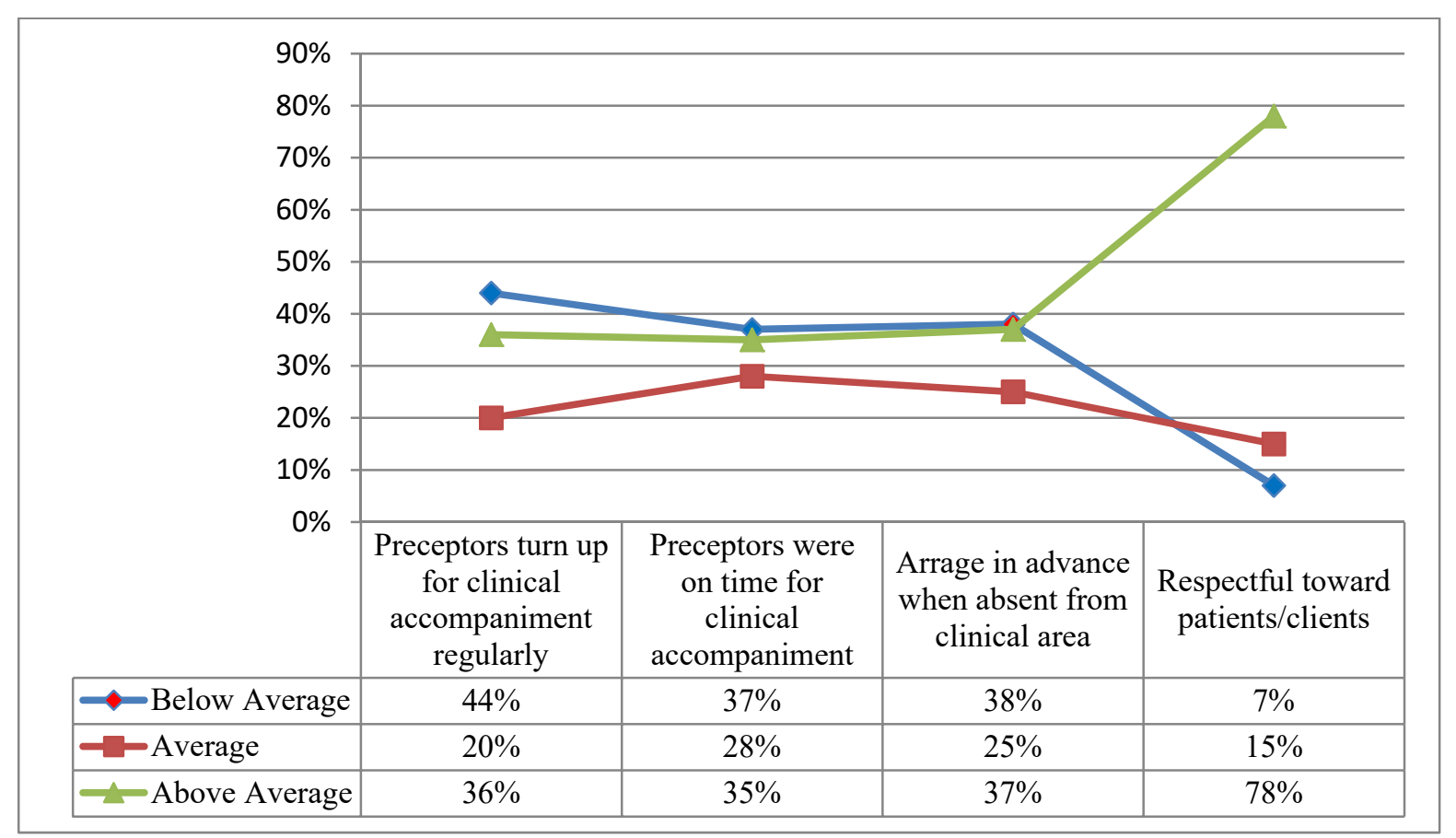

Figure 5. Student perceptions regarding the overall professional conduct of the preceptors

Figure 5 revealed that the majority of the participants $(n=78 ; 78 \%)$ were of the opinion that the preceptors treated patients/clients with respect, a significant $44 \%(n=44)$ of the study participants indicated that the preceptors did not arrive for clinical accompaniment on a regular basis, while 37\% $(n=37)$ of the participants reported that preceptors were often not on time for clinical accompaniment. Finally, the study found that $38 \%(n=38)$ of the participants reported that the preceptors did not arrange their absence from the clinical area in advance.

\subsection{Validity and Liability}

The questionnaire was administered in a language which both the respondents and the researcher understood. Data quality checks were conducted in the field as well as before the data processing to ensure the completeness and consistency of the data. In order to ensure the reliability of the study, a pilot study (inter-rater reliability) was undertaken to determine the accuracy and consistency of the research instrument used. In addition, the instrument was thoroughly checked for reliability by some of the supervisors who were expert in quantitative research.

\section{Discussion}

The purpose of the study was to assess and describe the students' perception on the use of preceptors for improvement of student nurses'clinical competences. This section, presents discussion of the findings with regard to facilitation by the preceptors of: clinical teaching, student support and professional conduct.

\subsection{Clinical Teaching}

As reported by $37 \%(n=37)$ of the participants, the study showed that, overall, the preceptors' teaching methods were not well organised. These results were found to be consistent with the findings of similar studies conducted in Malawi by Phuma-Ngaiyaye, Chipeta and Bvumbwe, (2017) with Kimberly et al. (2014), also confirming the same results on clinical teaching by preceptors. In other words, the findings of this study disagrees that preceptors are to facilitate student teaching in an organised manner as is well supported in the existing literature.

The study also revealed that $51 \%(n=51)$ of the respondents reported that their preceptors encouraged the students to interact with each other by providing them with difference perspectives on their clinical learning in order to increase their knowledge of clinical parctice. Student nurses who feel safe and accepted within the clinical environment possess the courage required to interact with other students in demanding situations and to assist in such situations, thus improving their clinical skills when addressing problems (Myrick \& Yonge, 2015). Similar findings were also reported in a study conducted in Malawi by Winston, Indiana and Chamberlin (2014), which highlighted importance of the preceptors to encourage students to interact as often as possible with their fellow students. 
It was reported in this study that the preceptors were giving the students an opportunity to explain their needs in relation to the demonstrations of procedures. These results are similar to those of Otoo (2016) where the use of a preceptor was found to be important, specifically stressing that preceptors should give nursing students an opportunity to discuss ways to improve demonstarttions of procedures.

\subsection{Student Support}

This study reported that $15 \%$ of the student nurses were happy with the compassionate and respectful treatment by the preceptors. These findings were similar to those from a study conducted in the United States of America by Winston et al. (2014) whose aim was to describe nursing students' experiences in relation to support from their preceptors. In this regard, the authors reported that the preceptors were treating the student nurses humanely and with respect. Phuma-Ngaiyaye, Bvumbwe and Chipeta (2017) concluded that preceptors'ongoing support and guidance for the students help the students to improve their clinical competence.

In addition to the results discussed above, $20 \%$ of the respondents in the study reported that when preceptors treat students as individuals and demonstrate a positive attitude towards them, the students' professionalism is improved, thereby contributing to increased role socialisation, enhancement of critical thinking, promotion of clinical competence and self-confidence. In a similar vein, the findings of a study conducted in the United States of America on preceptors' facilitation of the confidence level and critical thinking of student nurses, indicated that when students are accompanied on a daily basis by their preceptors, they develop a degree of critical thinking. In the current study, $30 \%$ of the respondents reported that working with the preceptors in the clinical setting increases their confidence. In conclusion, it was reported that the ongoing support and guidance received from the preceptors helped the students to improve their clinical competence. These findings are in line with the results of a study that reported that preceptorship contributes to the development of and improvement in the psychomotor skills of students (Otoo, 2016).

\subsection{Professional Conduct}

This study reported that there appeared to be poor communication channels between the training institutions, preceptors and students despite the importance of clear communication channels in ensuring effective clinical teaching and learning. In addition, the study revealed that a significant $44 \%(n=44)$ of the students reported that their preceptors did not arrive regularly for clinical accompaniment. Preceptors are supposed to act as a link between the students and their training institutions as well as between the students and clinical settings in order to foster communication (Phuma-Ngaiyaye, Bvumbwe, \& Chipeta, 2017). It is also of importance to note that the participants in this study $44 \%(n=44)$ indicated that preceptors do not use the time as required. The findings from this study therefore disagrees with Otoo (2016), who reported that preceptors use clinical time effectively.

Moreover, the findings revealed that preceptors often do not arrange in advance with their students about their planned absences from clinical practice. This is contrary to the assertion by Winston et al. (2014) that preceptors are supposed to be gatekeepers to the clinical settings because of their familiarity with the clinical environment as compared to that of both the nurse educators and the students.

\section{Conclusions}

The results of the study are of significant in different perspectives. The findings clearly showed that the use of preceptors to improve the clinical competence of nursing students had a positive impact on the students' clinical competence. The study also revealed that the preceptors have an important role to play, including clinical teaching, student support and professional conduct. However, based on the foregoing discussion, it may be concluded that the practice of using preceptors to improve students' clinical competence at the School of Nursing at Rundu campus was not without challenges, as was reflected by the minor shortcomings on the part of the preceptors. Thus, the results highlighted the need for well-articulated plans to address the challenges identified regarding the use of preceptors if the clinical competence of the student nurses is to be strengthened.

\section{Recommendations}

Based on the findings of the study, the following recommendations were made:

- It was found in this study that preceptors did not explain all procedures mentioned in the practical manuals. It is therefore recommended that preceptors should explain the procedures step by step to such a level that all the students understand them.

- It was noted in the study that preceptors were embarking on demonstrations to the students without the students knowing what was to be demonstrated. It is thus recommended that preceptors provide a timetable noting when, where and what will be demonstrated to the students on specific days of the week. 
- The study results revealed that the preceptors did not arrive regularly for clinical accompaniment; neither do they inform students in advance about their planned absences from clinical teaching. Accordingly, the study recommends that an attendance register be instituted as a monitoring tool to monitor the preceptors' utilization of clinical practice time and communication with the nursing student leaders on their availability.

- The study found that it appeared that preceptors tended to help the students only toward the end of the academic year. It is consequently suggested that preceptors should start with clinical teaching as early as possible in the academic year to avoid the students being overloaded by work toward the end of the semester.

- The study also revealed that the preceptors worked day shifts only and, therefore, those students allocated to work night shift did not have access to them. Accordingly, the study recommends that staff establishment should make provision for preceptors for night shifts.

\section{Study Delimitations and Limitations}

The study was delimited to one campus of the University of Namibia where the nursing programme was offered. This limited the generalisation of the study findings to other campuses and also to all nursing students enrolled for the Bachelor of Nursing (Honours) (Clinical) nursing programme at other campuses of the university. In addition, the data source was self-administered questionnaires on the perception of nursing students regarding the use of preceptors to improve their clinical competence rather than a direct observation of their assessment of their own clinical skills and practices. In addition, the participants may have interpreted the questions in different ways when completing the questionnaires and thus the aim of specific questions may have been lost because of the way in which the questionnaire was interpreted.

\section{Acknowledgements}

We wish to thank all the respondents who took the time to participate in this study. Without their participation, this study would not have been possible.

\section{Competing Interest Statement}

The authors declare that there was no conflict of interest on this study.

\section{References}

Brink, H., Van der Walt, C., \& Van Rensburg, G. (2018). Fundamentals of research methodology for healthcare professionals (3rd ed.). Cape Town, South Africa: Juta.

Bruce, C., Klopper, C., \& Mellish, M. (2015). Teaching \& learning the practice of nursing (5th ed.). Cape Town, South Africa: Heinemann.

Burns, N., \& Grove, K. S. (2014). The practice of nursing research: Conducting, critique, and Utilization (5th ed.). Texas: Elsevier Saunders.

Holloway, I., \& Wheeler, S. (2010). Qualitative research in nursing and healthcare. Cape Town, RSA: Juta.

Kimberly, H. K., Andrew, Y. L., Lynn, E., \& Marlene, W. D. (2014). Improving clinical competence and confidence of senior nursing students through clinical preceptorship. International Journal of Nursing, 1(2), 183-209. https://doi.org/10.15640/ijn.v1n2a1

Mashaba, G., \& Brink, H. (2016). Nursing education: An international perspective. Cape Town, South Africa: Heinemann.

Mellish, M., Brink, L., \& Paton, F. (2016). Teaching \& learning the practice of nursing (4th ed.). Johannesburg, South Africa: Heinemann.

Myrick, F., \& Yonge, O. (2015). Nursing preceptorship: Connecting practice \& education. Philadelphia: Lippincott Williams \& Wilkins. Cape Town, RSA: Heinemann.

Otoo, G. N. (2016). Effects of undergraduate nursing student-preceptor relationship on the students self-reported clinical competence, self-esteem, and readiness to work as a registered nurse (Thesis and Dissertation). Retrieved from http://digitalcommons.molloy.edu/etd/8

Phuma-Ngaiyaye, E., Chipeta, E., \& Bvumbwe T. (2017). Using preceptors to improve nursing students' clinical learning outcomes: A Malawian students' perspective. International Journal of Nursing Science, 4(1), 164-168. https://doi.org/10.1016/j.ijnss.2017.03.001 
Polit, F., \& Beck, T. (2016). Essentials of nursing research: Appraising evidence for nursing practice. UK: Wiley-Blackwell.

Tangwa, Y. O., \& Shehnaaz, M. M. (2018). Importance of the preceptor-preceptee relationship in creating well prepared professionals: A make or break experience. Global Journal of Health Science, 11(1), 97-110. https://doi.org/10.5539/gjhs.v11n1p1

Winston, S., Indiana, E., \& Chamberlin, A. (2014). Student perceptions of preceptorship learning outcome in BSN programs. Journal of Nursing Education and Practice, 4(5), 160-165. https://doi.org/10.5430/jnep.v4n5p73

\section{Copyrights}

Copyright for this article is retained by the author(s), with first publication rights granted to the journal.

This is an open-access article distributed under the terms and conditions of the Creative Commons Attribution license (http://creativecommons.org/licenses/by/4.0/). 